\title{
O preço do altruísmo
}

\section{The price of altruism}

\author{
Felipe A. P. L. Costa \\ Mestre em Ecologia pela Universidade Estadual de Campinas. \\ meiterer@hotmail.com
}

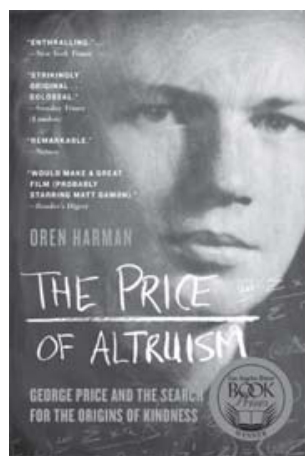

HARMAN, Oren. The price of altruism: George Price and the search for the origins of kindness. New York: W. W. Norton, 2010. 464p.
$\mathrm{E}$ m termos estritamente biológicos, o altruísmo pode ser entendido como um padrão de comportamento no qual a ação de um indivíduo resulta em benefícios para um segundo indivíduo, mesmo quando isso implica prejuízo imediato ao praticante da ação. Há uma rica e variada literatura de divulgação sobre o assunto, também em português - por exemplo, A formiga e o pavão (Cronin, 1995), O animal moral (Wright, 1996) e As origens da virtude (Ridley, 2000).

Em 2010, a editora nova-iorquina W. W. Norton lançou The price of altruism ( $\mathrm{O}$ preço do altruísmo), o último livro de Oren Harman, historiador da ciência e professor universitário em Israel. Trata-se de uma biografia do cientista estadunidense George Price, tendo como pano de fundo a história dos estudos sobre o altruísmo, desde meados do século XIX aos dias de hoje.

O grande mérito do livro de Harman e, penso eu, a razão do seu sucesso, é seu personagem central. A despeito de feitos científicos notáveis e de uma trajetória de vida das mais intrigantes, Price segue sendo um personagem virtualmente desconhecido, não só do público leigo em geral, mas dentro da própria comunidade científica. Afinal, quem foi George Price e que legado ele nos deixou?

O químico George Robert Price nasceu em Nova York, em 6 de outubro de 1922, e faleceu em Londres, na primeira semana de janeiro de 1975. Estudou na Universidade de Chicago, onde concluiu a graduação em química (1943) e uma pós-graduação (1946). Durante a Segunda Guerra Mundial, trabalhou no chamado Projeto Manhattan, empreendimento científico-militar do governo dos EUA que estava desenvolvendo a primeira bomba atômica. Foi lá que conheceu Julia Madigan, com quem se casou em 1947. O casal teve duas filhas, mas se divorciou em 1955.

Em 1966, Price foi operado para remoção de um câncer na tireoide. A cirurgia deixou sequelas - um de seus ombros ficou parcialmente paralisado. Em novembro de 1967, com o dinheiro que recebeu do seguro-saúde, largou o confortável emprego que tinha na época e mudou-se sozinho para Londres. Estudou por conta própria sobre vários assuntos ao mesmo tempo, atrás de inspiração. Terminou fixando sua atenção na teoria evolutiva. Ficou particularmente interessado em questões relacionadas ao altruísmo - afinal, se a seleção natural é o principal 'motor' da evolução, não deveria o egoísmo biológico ser um fenômeno ainda mais evidente e universal? Como explicar o surgimento e a manutenção 
do cuidado parental em tantas espécies animais? Mais especificamente, como o cuidado parental poderia ter-se estabelecido na espécie humana? Como explicar a origem de grupos familiares?

Deparou-se então com as ideias do biólogo inglês William D. Hamilton (1936-2000). Em 1964, Hamilton havia publicado um artigo sobre o altruísmo que logo se converteria em um marco na história da biologia evolutiva. Price ficou intrigado com o texto e, em março de 1968, enviou uma carta ao biólogo inglês. No ano seguinte, após Hamilton regressar de uma viagem ao Brasil, enfim estabeleceram contato - algo que marcaria para sempre a vida de ambos. Ainda em 1968, travou relações com John Maynard Smith (19202004), outro biólogo inglês que estava inovando as bases da teoria evolutiva.

Entre 1968 e 1972, Price trabalhou no prestigioso Laboratório Galton, do Colégio Universitário de Londres, período durante o qual escreveria - sozinho ou em coautoria três artigos fundamentais. Cada um deles representa um feito intelectual notável e, juntos, constituem expressivo e importante legado científico - um legado que não só marcaria a biologia evolutiva, mas que verdadeiramente ajudou a moldar a história recente da disciplina.

A primeira de suas três contribuições foi a elaboração de uma expressão matemática para a seleção natural (Price, 1970). Tal expressão, conhecida hoje como equação de Price, mostra como um caráter hereditário pode evoluir de uma geração a outra, dependendo apenas da contribuição que oferece à aptidão dos seus portadores. ${ }^{1}$

A segunda grande contribuição foi mostrar que a chamada teoria dos jogos, cuja formulação original visava equacionar fenômenos de economia e comportamento humano, poderia ajudar a resolver vários problemas biológicos. Embora seja costume creditar esse pioneirismo apenas a Maynard Smith, ele próprio fez questão de frisar que sua formulação do conceito de estratégia evolutivamente estável (EEE) foi inspirada na leitura de um manuscrito de Price sobre combates ritualizados entre animais. ${ }^{2}$

A história desse artigo é por si só inspiradora, mostrando que para ser um grande cientista não é necessário esfaquear ninguém pelas costas. Em 1968, Price havia submetido um manuscrito à avaliação e eventual publicação na revista científica Nature. Atendendo a uma solicitação da revista, Maynard Smith teve acesso privilegiado a esse material na condição de revisor. Assim, como havia acontecido com Hamilton um pouco antes, quando tomou conhecimento da equação de Price para a seleção natural, Maynard Smith de pronto percebeu os possíveis desdobramentos do que tinha diante de si. Fez contato com o autor, oferecendo ideias e material adicional. O manuscrito original de Price, porém, jamais foi publicado. Após uma série de contratempos, uma versão modificada foi publicada cinco anos depois, agora em coautorias (Smith, Price, 1973).

A terceira grande contribuição tem a ver com a elaboração de uma versão mais detalhada e inteligível de um modelo matemático proposto em 1930 pelo matemático e naturalista inglês Ronald A. Fisher (1890-1962). Até então, o chamado teorema fundamental da seleção natural era mais um objeto de veneração do que propriamente de compreensão. A formulação original era um tanto obscura, levando a uma interpretação que contradizia os argumentos e o raciocínio adotados pelo próprio Fisher. A derivação proposta por Price mostra como a formulação original poderia ser traduzida em termos biológicos mais compreensíveis (Price, 1972). 
Em novembro de 1973, quando o artigo em coautoria com Maynard Smith finalmente apareceu, George Price já estava com a cabeça em outro lugar. Desde meados de 1970, após uma longa trajetória de ateísta militante ${ }^{3}$, ele se havia convertido ao cristianismo e estava agora levando sua opção às últimas consequências. Decidiu doar seus bens, além de transformar seu confortável apartamento em abrigo para alguns despossuídos. Às vezes, havia tanta gente, que ele próprio tinha de dormir fora de casa. ${ }^{4}$

Adotou o costume de vagar pelas ruas, perguntando aos sem-teto que encontrava o que poderia fazer para ajudá-los. Em dezembro de 1972, foi hospitalizado com sinais de uma possível tentativa de suicídio; recuperou-se e voltou a trabalhar - foi após essa crise que ele concluiu sua contribuição para a última versão do artigo com Maynard Smith. Interpretou a própria recuperação como um sinal de que ele era o portador de alguma mensagem divina. A partir de então, em meio a altos e baixos, sua instabilidade mental não iria mais regredir.

Hamilton e Maynard Smith insistiam para que ele colocasse suas ideias científicas no papel. Price, no entanto, parecia cada vez menos interessado em publicar artigos científicos. Em junho de 1973, livrou-se dos seus últimos pertences, incluindo o próprio apartamento em que morava. Nessa época, ocupava a maior parte dos seus dias com trabalhos de assistência social. Seu crescente envolvimento com essas atividades terminou gerando um clima ruim para ele no Laboratório Galton.

Decidiu afastar-se ainda mais do mundo acadêmico, passando a esconder o que fazia. Por fim, a bolsa que recebia terminou, e ele não se importou em renová-la. Em março de 1974, vivendo como um sem-teto, Price foi morar na casa de uma senhora que ele próprio já havia ajudado. Arranjou um emprego noturno, mas logo o abandonou. Em agosto, foi morar no segundo andar de um prédio abandonado, situado a poucos quarteirões do seu antigo apartamento. Apaixonou-se por uma artista estadunidense, bem mais nova do que ele, cujo estúdio ficava no primeiro andar do prédio. Em cartas aos familiares e amigos, dizia que tinha planos de se casar de novo e voltar a morar nos Estados Unidos.

Em dezembro, passou alguns dias na casa da família Hamilton. Quando partiu, no dia 19, parecia bem de saúde. Combinaram um reencontro para o Ano Novo. Os problemas, porém, se precipitaram, e os fatos tomaram outro rumo. Na primeira semana de 1975, George Price foi tragado pela última crise de sua vida: em 6 de janeiro, seu corpo foi encontrado no apartamento em que morava. As evidências levaram à conclusão de que ele se suicidara, cortando a artéria carótida na altura do pescoço.

A despeito do notável legado científico que deixou, George Price segue sendo uma figura virtualmente desconhecida. A própria comunidade científica demorou a reconhecer a relevância do seu trabalho. Foram necessárias mais de duas décadas após a sua morte até que aparecesse um primeiro artigo com alguma visibilidade chamando a atenção para a relevância do seu trabalho.

Coube ao biólogo estadunidense Steven A. Frank quebrar o gelo (Frank, 1995). A partir de então, apareceram outros artigos chamando a atenção para o seu legado, com destaque para uma pequena e valiosa biografia escrita por James Schwartz (2000). Nesse meio-tempo, também começaram a surgir artigos fora da esfera estritamente biológica, principalmente por causa do alcance e da pertinência da equação de Price para o entendimento de processos 
seletivos em economia, linguística, psicologia etc. A publicação do livro de Oren Harman é, até certo ponto, fruto desse processo.

Os leitores brasileiros dispõem de poucas informações a respeito de George Price. A rigor, o único comentário significativo em português que consegui encontrar está no livro As origens da virtude (Ridley, 2000). Não ocupa, porém, mais do que um parágrafo de 11 linhas, ao longo do qual o autor chama mais atenção para os distúrbios psicológicos de Price do que para a sua sagacidade intelectual. E o pior: não ressalta a importância de seu legado.

George Price, com todos os problemas psicológicos que possa ter tido, esteve lado a lado não de um, mas sim de dois gigantes da biologia evolutiva, John Maynard Smith e William D. Hamilton. Nessa história, ele não foi apenas um coadjuvante, mas um verdadeiro protagonista. Uma história que terminou trágica e precocemente no inverno londrino de 1975 e cujos detalhes, até alguns anos atrás, eram de conhecimento apenas de familiares e um ou outro amigo.

\section{NOTAS}

${ }^{1}$ Em termos biológicos, aptidão é uma grandeza que mede a contribuição relativa de diferentes indivíduos na composição genética da próxima geração de descendentes.

${ }^{2}$ Uma EEE pode ser descrita como uma combinação de fenótipos capazes de coexistir de modo indefinido em uma mesma população. Tal convivência é possível graças à estabilidade gerada pelas frequências relativas dos próprios fenótipos.

${ }^{3}$ Talvez o principal fator a contribuir para a ruína do seu casamento; Julia Madigan era católica praticante.

${ }^{4}$ Uma atitude que me faz pensar em alguém com traços de Dorothy Day (Moira Kelly) e Peter Maurin (Martin Sheen), retratados no filme Celebração dos anjos: a história de Dorothy Day (Entertaining angels: the Dorothy Day story, 1996).

\section{REFERÊNCIAS}

CRONIN, Helena.

A formiga e o pavão. Campinas: Papirus. 1995.

FRANK, Steven A.

George Price's contributions to evolutionary genetics. Journal of Theoretical Biology, s.l., v.175, n.3, p.373-388. 1995.

PRICE, George R.

Fisher's 'fundamental theorem' made clear. Annals of Human Genetics, London, v.36, p.129-140. 1972.

PRICE, George R.

Selection and covariance. Nature, London, v.227, p.520-521. 1970.
RIDLEY, Matt.

As origens da virtude. Rio de Janeiro: Record. 2000.

SCHWARTZ, James.

Death of an altruist. Lingua Franca, New York, v.10, n.5, p.51-61. 2000.

SMITH, John Maynard; PRICE, George R. The logic of animal conflict. Nature, London, v.246, p.15-18. Nov. 1973.

WRIGHT, Richard.

O animal moral. Rio de Janeiro: Campus. 1996. 